Article

\title{
A Selective G-Quadruplex DNA-Stabilizing Ligand Based on a Cyclic Naphthalene Diimide Derivative
}

\author{
Md. Monirul Islam ${ }^{1}$, Satoshi Fujii ${ }^{2}$, Shinobu Sato ${ }^{1}$, Tatsuo Okauchi ${ }^{1}$ and Shigeori Takenaka ${ }^{1, *}$ \\ 1 Department of Applied Chemistry, Kyushu Institute of Technology, Kitakyushu, \\ Fukuoka 804-8550, Japan; E-Mails: monirbtge@takenaka.che.kyutech.ac.jp (M.M.I.); \\ shinobu@che.kyutech.ac.jp (S.S.); okauchi@che.kyutech.ac.jp (T.O.) \\ 2 Department of Bioscience and Bioinformatics, Kyushu Institute of Technology, Iizuka, \\ Fukuoka 820-8502, Japan; E-Mail: s.fujii@bio.kyutech.ac.jp \\ $\dagger$ These authors contributed equally to this work. \\ * Author to whom correspondence should be addressed; E-Mail: shige@che.kyutech.ac.jp; \\ Tel./Fax: +81-93-884-3322.
}

Academic Editor: Jean Jacques Vanden Eynde

Received: 8 May 2015 / Accepted: 8 June 2015 / Published: 12 June 2015

\begin{abstract}
A cyclic naphthalene diimide (cyclic NDI, 1), carrying a benzene moiety as linker chain, was synthesized and its interaction with G-quadruplex DNAs of a-core and a-coreTT as a human telomeric DNA, c-kit and c-myc as DNA sequence at promoter region, or thrombin-binding aptamer (TBA) studied based on UV-VIS and circular dichroism (CD) spectroscopic techniques, thermal melting temperature measurement, and FRET-melting assay. The circular dichroism spectra showed that 1 induced the formation of different types of G-quadruplex DNA structure. Compound 1 bound to these G-quadruplexes with affinities in the range of $10^{6}-10^{7} \mathrm{M}^{-1}$ order and a 2:1 stoichiometry. Compound 1 showed 270-fold higher selectivity for a-core than dsDNA with a preferable a-core binding than a-coreTT, c-kit, c-myc and TBA in the presence of $\mathrm{K}^{+}$, which is supported by thermal melting studies. The FRET-melting assay also showed that $\mathbf{1}$ bound preferentially to human telomeric DNA. Compound 1 showed potent inhibition against telomerase activity with an IC50 value of $0.9 \mu \mathrm{M}$ and preferable binding to G-quadruplexes DNA than our previously published cyclic NDI derivative 3 carrying a benzene moiety as longer linker chain.
\end{abstract}


Keywords: cyclic naphthalene diimide; G-quartet; human telomeric DNA; promoter region; promoter region; thrombin-binding aptamer

\section{Introduction}

Guanine-rich DNA sequences which mainly originate in important regions of the oncogene promoters, telomere, mRNA, ribosomal DNA (rDNA), and thrombin-binding aptamer (TBA) can form G-quadruplex structures [1-3]. G-quadruplex DNAs, formed at the telomeric end, can inhibit telomere elongation by telomerase, which are activated in $80 \%-85 \%$ cancer cells, leading to inhibition of telomerase activity $[1,4]$. G-quadruplex DNAs is known to be formed at promoter regions of the human oncogene that can regulate gene expression at the transcriptional level [3]. DNA aptamers bind to thrombin and inhibit thrombin-catalyzed fibrin, resulting in blood clotting [2]. Thus, guanine-rich sequences have become a very promising target for the development of new anticancer drugs and therapeutic applications, which was attracted a lot of research interest during the last few decades and a few of the resulting compounds have entered preclinical or clinical trials [3].

It has been reported that guanine-rich oligonucleotides could form G-quadruplexes via Hoogsteen hydrogen bonding among four guanine bases arranged in a square planar configuration [4]. G-quadruplex DNA shows diverse structural polymorphism; G-quadruplex DNA can be either parallel or antiparallel, even both conformations (termed hybrid) in some cases [5,6]. This G-quadruplex DNA can fold as a mixture of several different quadruplex forms depending on DNA sequence and extrinsic cation which offers a platform to induce and stabilize the quadruplexes by using small organic molecules $[5,6]$. This common structural feature poses challenges for the design of ligands with considerable selectivity toward one type of quadruplex over other G-quadruplex structures [6].

Small molecules that stabilize the G-rich single-strand DNA overhang into G-quadruplex can be considered as potential cancer and therapeutic agents [3]. A number of G-quadruplex-binding small molecules have been reported in the last few decades $[3,7,8]$. Several diverse structural ligands, including telomestatin, oxazole, cationic TMPyP4, anthraquinone, perylene, acridine, and ethidium derivatives have been investigated to evaluate their ability to interact with G-quadruplex DNA and observe their biological functions $[3,7,8]$. There are a number of macrocyclic structures that have been developed in the last few years as G-quadruplexes DNA binding ligands such as BQQ1, telomestain, oxazole, porphyrin, etc. [9], which is a well-established technique to improve the development of G-quadruplex DNA selective drugs. A common feature of these G-quadruplex-binding molecules is the presence of an extended aromatic ring system that allows binding through $\pi-\pi$ overlap of terminal G-tetrads [5,9]. Large flat aromatic planar molecules stack on G-tetrads and show high binding selectivity [6]. Non-planar molecules that stack with G-quadruplexes are very rare and bindings are moderate [6]. Some of these G-quadruplex-binders include porphyrin derivatives, oxazoles, perylene derivatives and similar systems [10] that have fused $\pi$-ring systems within the molecule and showed various binding selectivity with the G-quadruplexes' DNA structure. Nowadays, the researchers are focusing on developing G-quadruplex DNA structure-specific and selective binding ligands [6,9] which are important for drug development, cancer research and therapeutic application studies. 
Naphthalene diimides (NDIs) are very potent G-quadruplex-binding ligands with high cellular toxicity, which is able to effectively stabilize the terminal G-quartet of a G-quadruplex by stacking interactions [11,12]. Over the last few years a number of NDI-based compounds have been developed in part by exploiting the available NDI-G-quadruplexes structures [13-21]. In our previous studies, we already reported interaction studies of some cyclic NDI derivatives and h-telo 22 G-quadruplex DNA which can inhibit telomerase activity at low concentration [10,22]. In our present work, we synthesized new compound 1 by cyclization with the linker chain of a tertiary amino group and amide group through benzene to compare the binding selectivity with our previously reported compound 3 [10] (Figure 1). Compound 1 is expected to show reduced binding to dsDNA and increased binding affinity for G-quadruplexes DNA because of its shorter linker substituents. We have also sought to compare the binding selectivity among the various structures of G-quadruplex DNA. We have characterized the binding selectivity and stability of $\mathbf{1}$ to G-quadruplexes' DNA present in the promoter region (c-myc and c-kit), thrombin binding aptamer (TBA) and human telomeric region (a-core and a-coreTT) by UV-Vis spectroscopy, circular dichroism (CD) spectroscopy, thermal melting studies, TRAP assay and FRET-melting assay [23] experiments.
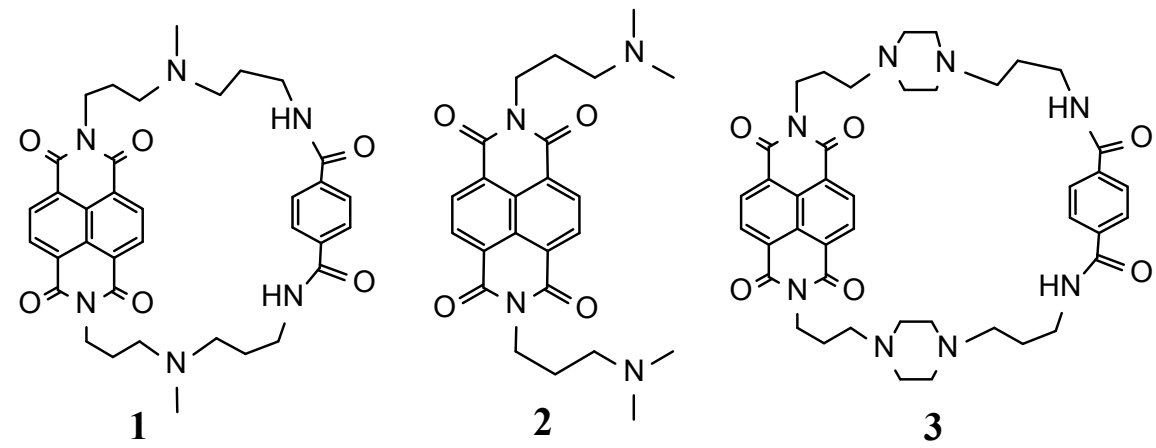

Figure 1. Chemical structures of 1, 2 and $\mathbf{3}$ (3 taken from [10]).

\section{Results and Discussion}

\subsection{UV-Vis Absorption Titration}

To obtain the binding constant and the number of bound molecules for the interaction of 1 and non-cyclic naphthalene diimide $\mathbf{2}$ with different DNA forms such as human telomere (a-core and a-coreTT) [4,24,25], promoter region (c-kit and c-myc) [26-28] and thrombin-binding aptamer (TBA) $[29,30]$ their absorption spectra were investigated. Figure $2 \mathrm{~A}$ shows a representative spectrophotometric titration of 1 with human telomeric G-quadruplex DNA (a-core) in $\mathrm{K}^{+}$ion. It shows a maximum absorption at $384 \mathrm{~nm}$. Addition of increasing amounts of G-quadruplex DNAs to 1 resulted in large hypochromicities $(45 \%-60 \%)$ and a noticeable small red shift (3-8 nm) was observed. These spectral features are suggestive of end-staking binding rather than groove binding (Supplementary Figure S1). We observed isosbestic points at $392 \mathrm{~nm}$ and $395 \mathrm{~nm}$ of 1 for G-quadruplex DNAs and duplex DNA, respectively. The presence of isosbestic points indicated the equilibrium between the bound and free ligand. For comparison, we also investigated the interaction of 1 with dsDNA. Upon the addition of increasing amounts of dsDNA to $\mathbf{1}$, smaller hypocromic shifts $(25 \%-30 \%)$ and red shifts $(2-4 \mathrm{~nm})$ were observed than for G-quadruplexes DNA, suggesting this compound is not a good dsDNA binder (Figure 2B). The Scatchard plot representing the 
binding between 1 and a-core $(\mathrm{KCl})$ is presented in Figure $2 \mathrm{C}$. The Scatchard plot was analyzed by the McGhee-von Hippel Scatchard equation [31]. The solid line in Figure 2C represents the best fit of the experimental value to the McGhee-von Hippel equation. For dsDNA saturation of binding curves was not achieved; therefore, estimation of $K$ values using the Scatchard equation was impossible. However, $n K$ values were estimated using the Benesi-Hildebrand method [32]. Ligand binding affinity to dsDNA does not depend on the nature of the metal cation, such as sodium and potassium ions. In the presence of sodium and potassium ions compound $\mathbf{2}$ binds to dsDNA approximately 20 times stronger than $\mathbf{1}$.

A

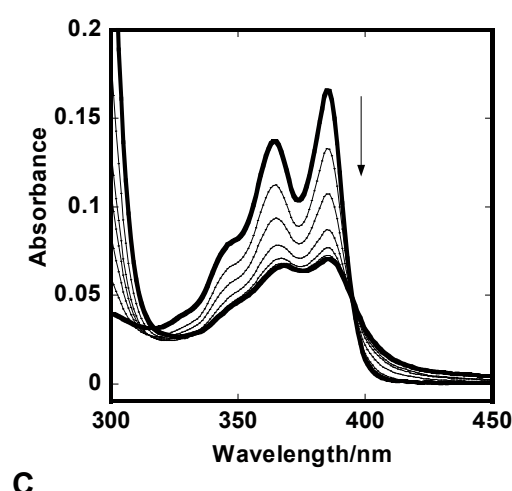

C

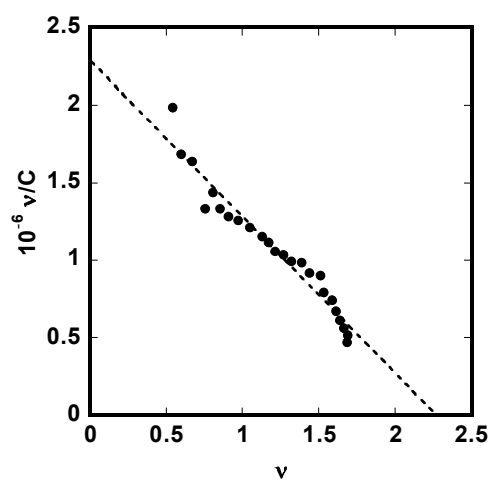

B

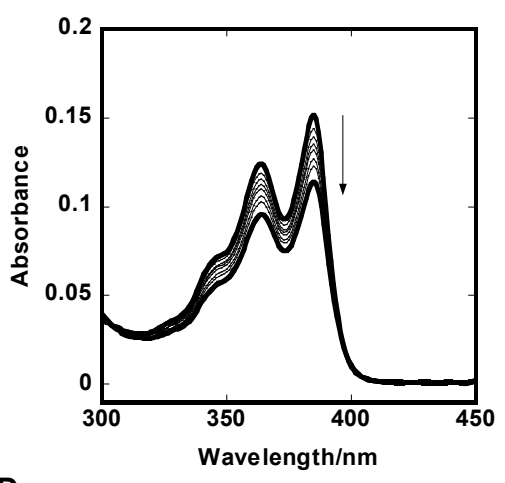

D

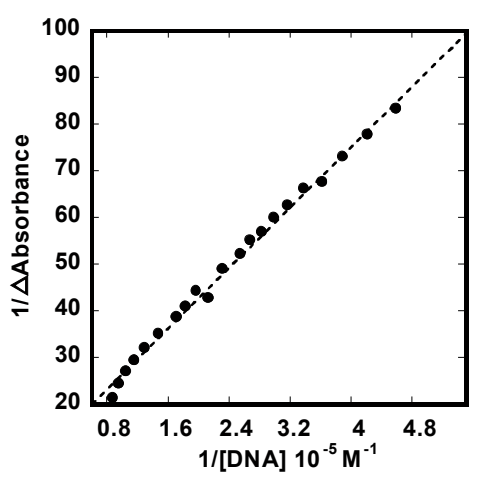

Figure 2. Spectral shifts of $5 \mu \mathrm{M} 1$ on titration with $0,1.4,2.9,4.4,5.8,8.7$ and $14 \mu \mathrm{M}$ a-core (A) or 0, 2.0, 5.0, 10, 20, 30, and $40 \mu \mathrm{M}$ dsDNA (B) in $50 \mathrm{mM}$ Tris- $\mathrm{HCl}(\mathrm{pH} 7.4)$ and $100 \mathrm{mM} \mathrm{KCl}$. Scatchard plots for binding of $\mathbf{1}$ to a-core $(\mathbf{C})$ and Benesi-Hildebrand plot for binding of 1 to dsDNA (D).

The intrinsic binding constants $(K)$ of $\mathbf{1}$ and $\mathbf{2}$ to G-quadruplexes DNA and dsDNA are summarized in Table 1 . We already reported that 3 carrying a benzene moiety as longer linker chain showed higher binding affinity to either G-quadruplexes DNA or dsDNA than 2 [10]. In our present study, we also found similar binding constant trends for G-quadruplexes DNA in the range of $10^{6}-10^{7} \mathrm{M}^{-1}$ with $n=2$, which are an almost five times higher binding affinity of $\mathbf{1}$ compared with the non-cyclic derivative $\mathbf{2}$. Comparing with 3 [10], 1 showed almost three times higher binding affinity to a-core and 70 times weaker binding to dsDNA. Compound 1 showed approximately 200 higher selectivity to G-quadruplexes DNA than the previously reported 3 [10]. The comparison suggests that the shorter cyclic linker chain 1 showed higher specific binding to G-quadruplex DNAs than the previously reported longer linker chain compound 3 [10]. 
Table 1. Binding parameters and melting temperatures of $\mathbf{1}$ and $\mathbf{2}$ with a-core, a-coreTT, c-kit, c-myc, TBA and dsDNA.

\begin{tabular}{cccccccc}
\hline \multirow{2}{*}{ DNAs } & $\mathbf{1}$ & $\mathbf{2}$ & \multicolumn{3}{c}{$\mathbf{T m} /{ }^{\circ} \mathbf{C}$} & \multicolumn{2}{c}{$\Delta \mathbf{T m} /{ }^{\circ} \mathbf{C}$} \\
\cline { 2 - 8 } & $10^{-6} \mathrm{~K} / \mathrm{M}^{-1}$ & $n$ & $10^{-6} \mathrm{~K} / \mathrm{M}^{-1}$ & $n$ & $\mathrm{DNAs}$ & $\mathbf{1}$ & $\mathbf{2}$ \\
\hline a-core $\left(\mathrm{K}^{+}\right)$ & $10 \pm 0.5^{\mathrm{a}}$ & 1.5 & $1.6 \pm 0.2^{\mathrm{a}}$ & 1.4 & $69^{\mathrm{c}}$ & 15 & 5 \\
a-core $\left(\mathrm{Na}^{+}\right)$ & $1.0 \pm 0.04^{\mathrm{a}}$ & 2.2 & $0.73 \pm 0.09^{\mathrm{a}}$ & 1.0 & $57^{\mathrm{c}}$ & - & 1 \\
a-coreTT $\left(\mathrm{K}^{+}\right)$ & $6.1 \pm 0.4^{\mathrm{a}}$ & 1.8 & $1.9 \pm 0.3^{\mathrm{a}}$ & 1.3 & $63.5^{\mathrm{c}}$ & 18 & - \\
TBA $\left(\mathrm{K}^{+}\right)$ & $3.5 \pm 0.2^{\mathrm{a}}$ & 1.4 & $0.49 \pm 0.04^{\mathrm{a}}$ & 1.1 & $50.5^{\mathrm{c}}$ & 11 & - \\
c-kit $\left(\mathrm{K}^{+}\right)$ & $1.9 \pm 0.18^{\mathrm{a}}$ & 1.4 & $0.74 \pm 0.05^{\mathrm{a}}$ & 1.7 & $54^{\mathrm{d}}$ & 11 & - \\
c-myc $\left(\mathrm{K}^{+}\right)$ & $4.0 \pm 0.3^{\mathrm{a}}$ & 1.7 & $1.5 \pm 0.2^{\mathrm{a}}$ & 1.6 & $70^{\mathrm{e}}$ & 15 & - \\
dsDNA $\left(\mathrm{K}^{+}\right)$ & $0.037^{\mathrm{b}}$ & - & $0.60 \pm 0.04^{\mathrm{a}}$ & 2.8 & $49^{\mathrm{c}}$ & 0.3 & 12 \\
dsDNA $\left(\mathrm{Na}^{+}\right)$ & $0.037^{\mathrm{b}}$ & - & $0.60 \pm 0.08^{\mathrm{a}}$ & 3.0 & $49^{\mathrm{c}}$ & 0.3 & 12 \\
\hline
\end{tabular}

Condition: Binding constant $(K): 50 \mathrm{mM}$ Tris- $\mathrm{HCl}(\mathrm{pH} 7.4)$ and $100 \mathrm{mM} \mathrm{NaCl}$ or KCl; ;: Scatchard analysis $(K)$;

b: Bensi-Hildebrand analysis $(n K)$; Thermal melting: [ligand]:[DNA] = 2:1, $50 \mathrm{mM}$ Tris- $\mathrm{HCl}(\mathrm{pH} 7.4) ;{ }^{\mathrm{c}}: 100 \mathrm{mM}$

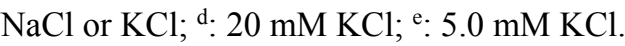

In comparison with our previous report [10], the linker chain of $\mathbf{1}$ and $\mathbf{3}$ may play an important role in the binding with G-quadruplexes DNA over dsDNA. The amide chains of $\mathbf{1}$ and $\mathbf{3}$ might be more effective in reducing binding with dsDNA because of the NDI moiety site blocks the aliphatic chain from intercalating in the benzene part. Moreover, the benzene part itself also prevents binding of $\mathbf{1}$ and 3 from threading intercalations with dsDNA. However, as we have reported earlier [33], 1 and $\mathbf{3}$ showed affinity to calf thymus DNA (CT-DNA), Poly[d(A-T) $]_{2}$ and Poly[d(G-C) $]_{2}$ due to hydrophobic interaction between cyclic NDI derivatives and dsDNA. Compound 1 showed lower binding affinity to CT-DNA, poly[d(A-T) $]_{2}$ and poly $[\mathrm{d}(\mathrm{G}-\mathrm{C})]_{2}$ than $\mathbf{3}$ perhaps because of steric reasons, whereas, according to the computer modeling, the NDI moiety site of cyclic NDI derivatives incorporated to end staking onto the G-quartet. We have observed that $\mathbf{1}$ showed higher selectivity to G-quartet than $\mathbf{3}$ because the tertiary amino chain in the linker chain of $\mathbf{1}$ may have more compatibility to bind specifically with the G-quartet plane than the piperazine linker chain of $\mathbf{3}$.

In the presence of sodium ions the binding affinities of both ligands to basket-type tetraplex structures were much lower than G-quadruplexes in potassium solution. We already explained that this might be due to the fact that basket type a-core crosses its oligonucleotide chain over the G-quartet diagonally and disrupts access of $\mathbf{1}$ to the G-quartet plane [10].

In our present study, all the G-quadruplexes DNA showed higher binding constants $(K)$ with 1 than dsDNA. In potassium ion solution, 1 exhibited the highest binding affinity for mixed hybrid type a-core [24] with $K=1 \times 10^{7} \mathrm{M}^{-1}$, whereas diminished the binding affinity to dsDNA with $n K=3.7 \times 10^{4} \mathrm{M}^{-1}$. The binding data indicated that 1 has a 270 -fold preference for a-core over dsDNA. Table 1 shows the binding constants $(K)$ are $K=6.1 \times 10^{6} \mathrm{M}^{-1}$ for a-coreTT (hybrid type-2) [25], $K=1.9 \times 10^{6} \mathrm{M}^{-1}$ for c-kit (parallel propeller type) [27], $K=4.0 \times 10^{6} \mathrm{M}^{-1}$ for c-myc (parallel type) [27], $K=3.5 \times 10^{6} \mathrm{M}^{-1}$ for TBA (antiparallel chair type) [30] with 1, which represent a 165-, 51-, 108- and 95-fold binding preference over dsDNA $\left(K=3.7 \times 10^{4} \mathrm{M}^{-1}\right)$, respectively. The ratio of ligand per dsDNA used for binding was $n=3$, a reasonable result considering that a typical intercalator covers two base pairs upon binding to dsDNA, in addition to the expected relative difficulty in binding at terminal sites. The binding number 
of a ligand with G-quadruplexes DNA was estimated to be $n=2$, which may agree with an end-stacking binding of 1 to the external G-quartet planes of quadruplexes.

According to the above result, new compound 1 showed G-quadruplexes DNA structure-specific binding. Compound 1 showed the highest affinity to a-core DNA, which exhibits mixed type hybrid (hybrid-1 and hybrid-2) structures in $\mathrm{K}^{+}$[24] and possessed more than two drugs staking plane and binding loops. Computer modeling showed that $\mathbf{1}$ was stacked and bound to a mixed hybrid structure at various G-quadruplex staking planes, whereas a-coreTT exhibited hybrid-2 [25] type structures which have two G-tetrads staking planes and two binding sites. For this reason we observed that 1 showed the highest affinity with a-core. TBA exhibited an antiparallel chair type [29,30] structure which has G-quartet staking planes and binding loops, while c-kit and c-myc exhibited parallel type [27] propeller structures which possess two G-quartet staking planes, but binding loops are unusual for $\mathbf{1}$. According to the binding data, new compound $\mathbf{1}$ was revealed to be a most preferable and specific binder to telomeric G-quadruplexes DNA than promoter regions' G-quadruplex DNA as well as thrombin binding aptamer. The binding studies results are consistent with thermal melting studies where a-core showed the highest stabilization with $\mathbf{1}$. The binding site size ( $n$ values) obtained from binding studies of G-quadruplexes and $\mathbf{1}$ are consistent with the Job plot analysis from CD studies (Supporting Information Figure S2).

\subsection{Circular Dichroism (CD) Studies}

$\mathrm{CD}$ is a powerful method to differentiate the parallel, anti-parallel, and mixed-type secondary structure of G-quadruplex DNA. Compound 1 was interacted to investigate the effect of the compound binding on the conformation of the G-quadruplexes, which is shown in Figure 3. The CD spectrum of human telomere (a-core) G-quadruplex DNA showed a negative peak at $240 \mathrm{~nm}$, a shoulder peak at $265 \mathrm{~nm}$ and a positive peak at $290 \mathrm{~nm}$ (Figure 3A) in buffer containing $100 \mathrm{mM} \mathrm{KCl}$, supportive of a mixed hybrid type (hybrid-1 and hybrid-2) G-quadruplex structure [34,35]. The small positive peak at $265 \mathrm{~nm}$ was transformed increasingly into a negative peak at $260 \mathrm{~nm}$ together with an increase of the positive peak at $290 \mathrm{~nm}$ upon the addition of $\mathbf{1}$, suggesting the induction of a hybrid type structure. After addition of 1, a-core structure conformation changed a little from mixed hybrid type to hybrid-1 type [36]. In our previous study, we reported that in the presence of $\mathrm{Na}^{+}$ions, telomeric DNA exists in an antiparallel basket-type conformation. Upon addition of 1, this antiparallel basket-type structure was also retained [10].

The CD spectrum of human telomere (a-coreTT) G-quadruplex in buffer containing $100 \mathrm{mM} \mathrm{KCl}$ exhibits a negative peak at $240 \mathrm{~nm}$, a shoulder peak at $265 \mathrm{~nm}$ and a positive peak at $290 \mathrm{~nm}$ (Figure 3B) supportive of a hybrid-2 type G-quadruplex structure [34,35]. The small positive peak at $265 \mathrm{~nm}$ is transformed increasingly into a negative peak at $260 \mathrm{~nm}$ together with an increase of the positive peak at $290 \mathrm{~nm}$ upon the addition of $\mathbf{1}$, suggesting the induction of a hybrid type structure. After the addition of 1, a-core structure conformation changed a little from hybrid-2 type to hybrid-1 type [36].

In the presence of $100 \mathrm{mM} \mathrm{KCl}$ thrombin-binding aptamer (TBA, Figure 3C) exhibited a positive peak at $290 \mathrm{~nm}$, and a negative band at $250 \mathrm{~nm}$, supportive of an anti-parallel chair type G-quadruplex structure [30,37]. Upon the addition of $\mathbf{1}$, the negative peak transformed increasingly into at $260 \mathrm{~nm}$ together with an increase of the positive peak at $290 \mathrm{~nm}$, suggesting that the binding of 1 apparently does not disturb the structure of TBA, which is consistent with previous reports [37]. 
A
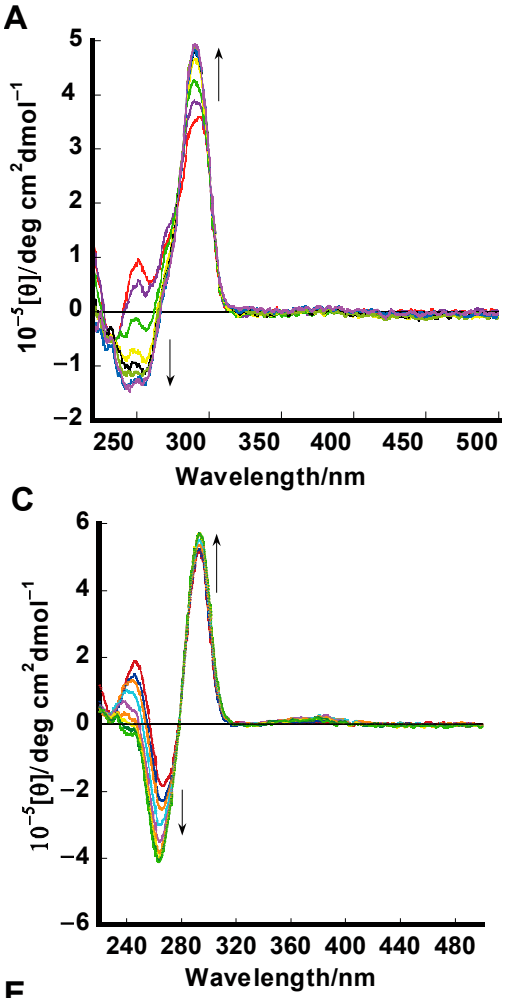

$\mathbf{E}$

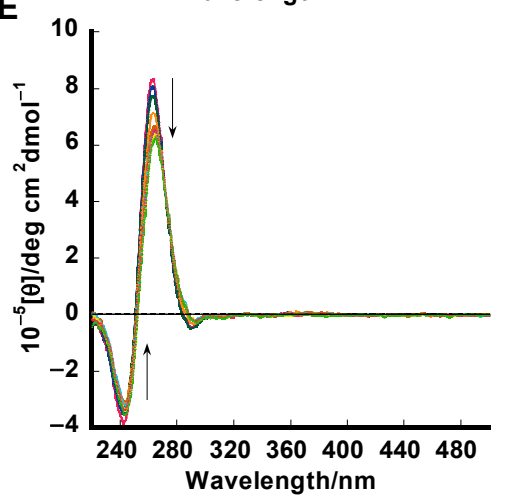

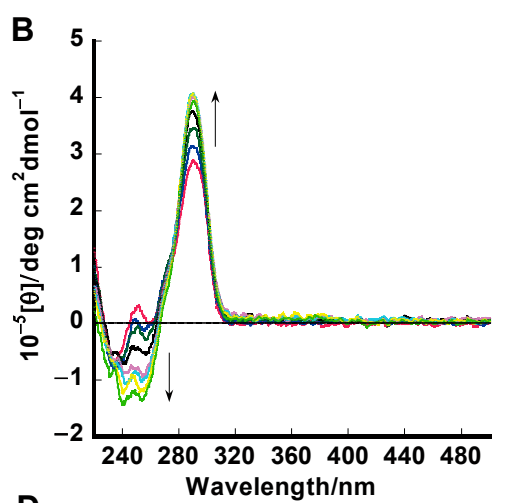

D

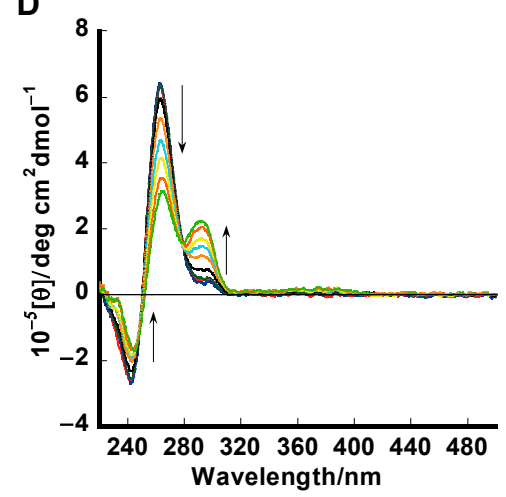

Figure 3. CD spectra of $1.5 \mu \mathrm{M}$ of a-core (A); a-coreTT (B); TBA (C); c-kit (D); c-myc (E) in $50 \mathrm{mM}$ Tris- $\mathrm{HCl}(\mathrm{pH} 7.4), 100 \mathrm{mM} \mathrm{KCl}$ in addition of $\mathbf{1}(0,0.38,0.75,0.80,2.25$, and $3.00 \mu \mathrm{M})$ at $25^{\circ} \mathrm{C}$.

Both c-myc and c-kit G-quadruplex (Figure 3D,E) exist in the presence of $\mathrm{K}^{+}$ions as a parallel structure, which has a characteristic positive peak centered around $262 \mathrm{~nm}$, a negative peak at $241 \mathrm{~nm}$ and a small shoulder peak at $290 \mathrm{~nm}$ [38,39]. After the addition of 1 to c-myc and c-kit G-quadruplex, a decrease of the CD peaks at $241 \mathrm{~nm}$ and $262 \mathrm{~nm}$ was observed, with no other significant change in the spectrum and the parallel structure was not change, which suggests ligand-dependent disruption of staking of G-quadruplex DNA. Upon the addition of 1, the c-kit structure shoulder peak at $290 \mathrm{~nm}$ increased little. This effect has also been observed previously by many research groups [40].

The Job plot analysis by CD studies (Supporting Information Figure S2) showed that CD studies of G-quadruplexes and $\mathbf{1}$ are consistent with binding studies where similar binding site sizes ( $n$ values) are obtained. 


\subsection{Thermal Melting Studies}

Thermal stabilization of various G-quadruplexes DNA and dsDNA in the presence of $\mathbf{1}$ was studied using the CD melting and UV-Vis melting experiment (Figure 4). Thermal melting of hybrid type telomeric quadruplex DNA (a-core and a-coreTT) was monitored at $290 \mathrm{~nm}$ in the presence of $\mathrm{K}^{+}$[25].
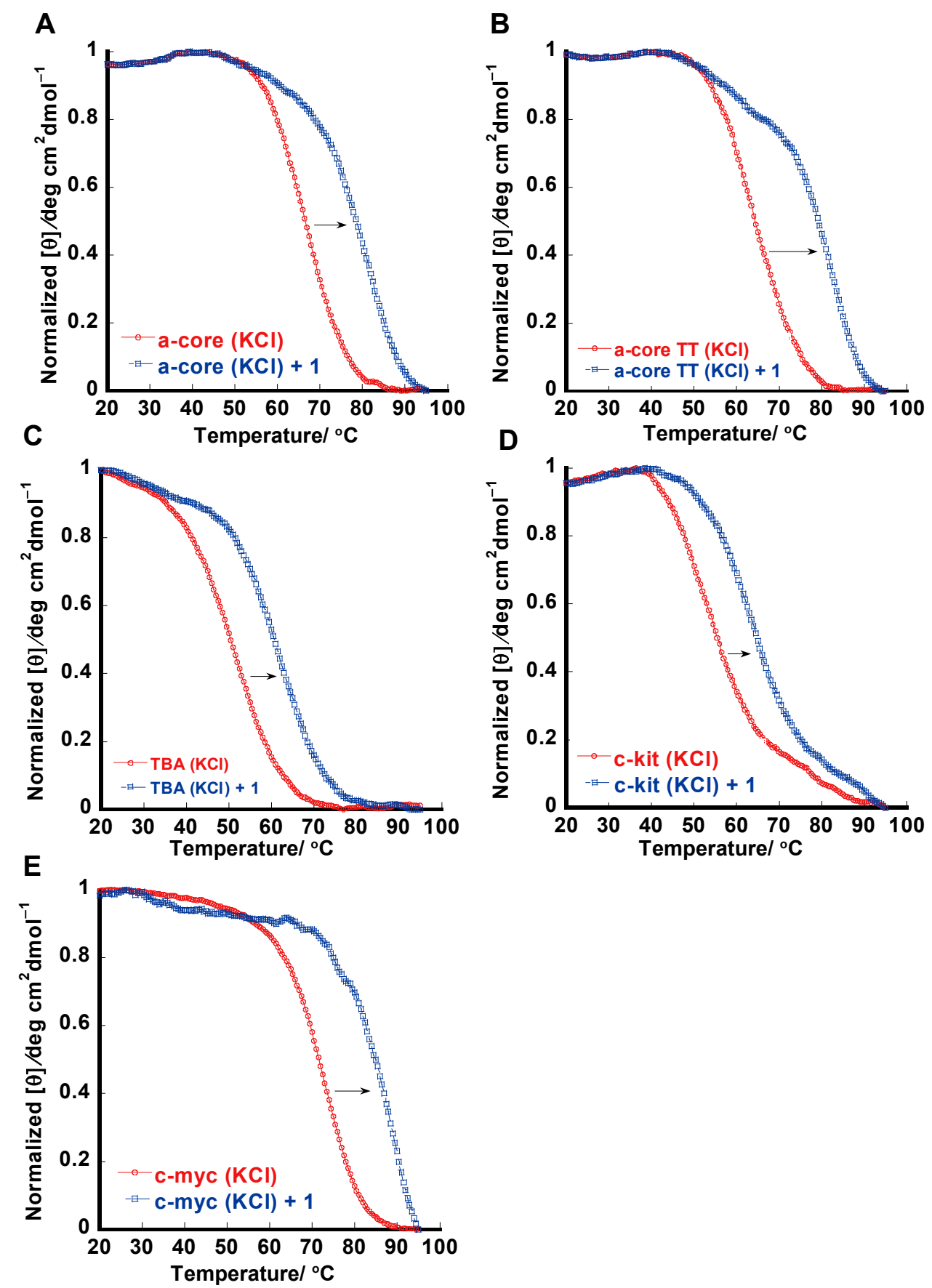

Figure 4. Melting profiles for a-core (A); a-coreTT (B); TBA (C); c-kit (D); c-myc (E) in the absence or presence of $\mathbf{1}$ in $50 \mathrm{mM}$ Tris- $\mathrm{HCl}$ (pH 7.4); $100 \mathrm{mM} \mathrm{KCl} \mathrm{(A-C);} 20 \mathrm{mM} \mathrm{KCl}$ (D); $5.0 \mathrm{mM} \mathrm{KCl}(\mathbf{E})$ and [ligand]:[DNA] $=2: 1$.

The $\mathrm{T}_{\mathrm{m}}$ value was observed around $69^{\circ} \mathrm{C}$ for a-core without 1 (Figure $4 \mathrm{~A}$ ). We observed that the interaction of 1 with telomeric DNA quadruplex enhanced the stability by $15^{\circ} \mathrm{C}$ for a-core and $18{ }^{\circ} \mathrm{C}$ 
for a-coreTT, which was approximately $3{ }^{\circ} \mathrm{C}$ higher for a-coreTT than a-core G-quadruplexes DNA (Table 1). Researchers already reported that thermal melting increased after addition of base to oligonucleotides [41]. In our previous report [10], we observed from the absorption spectra that 3 had the lowest binding affinity to a-core in sodium ion solution. Furthermore, dsDNA was monitored by UV-Vis melting studies. After the addition of a 1-fold $\mathbf{1}$ concentration, only a slight increase (up to $0.3{ }^{\circ} \mathrm{C}$ ) in thermal stability was observed (Table 1 and Supplementary Figure S3). These results underscore the fact that $\mathbf{1}$ selectively stabilizes telomeric quadruplex DNA as well as promoter and thrombin binding aptamer G-quadruplex DNA over dsDNA. In comparison with our previous report [10], compound 1 showed high stabilizing effect to a-core and very weak stabilizing effect to ds DNA.

The melting temperatures of antiparallel chair type thrombin binding aptamer quadruplex DNAs (TBA) were monitored at $290 \mathrm{~nm}$. Compound 1 increased the $\mathrm{T}_{\mathrm{m}}$ of TBA by $11{ }^{\circ} \mathrm{C}$ (Table 1). These results are consistent with previously published articles [30,37]. The melting temperatures of parallel promoter quadruplex DNAs such as c-kit and c-myc were monitored at $263 \mathrm{~nm}[39,40]$. In the case of the highly stable parallel c-kit and c-myc quadruplex DNA was highly stable at high salt concentration and a stable baseline curve was not achieved even above $90{ }^{\circ} \mathrm{C}$, so it is not possible to measure an accurate $\mathrm{T}_{\mathrm{m}}$ in this case, so we measured $\mathrm{T}_{\mathrm{m}}$ for c-kit and c-myc at low salt concentration. Compound 1 increased the $\mathrm{T}_{\mathrm{m}}$ of c-kit by $>11^{\circ} \mathrm{C}$ at $20 \mathrm{mM} \mathrm{K}^{+}$ion and the $\mathrm{T}_{\mathrm{m}}$ of c-myc by $>15^{\circ} \mathrm{C}$ at $5 \mathrm{mM} \mathrm{K}^{+}$ion solution (Table 1). This type of performance of c-kit and c-myc is consistent with previously published articles $[39,40]$. According to the above result, we can conclude that $\mathbf{1}$ preferably stabilizes telomeric quadruplex DNA than promoter and thrombin binding aptamer G-quadruplex DNA. CD melting results are consistent with binding and competition assay studies, where $\mathbf{1}$ showed preferable binding to human telomeric G-quadruplex.

\subsection{TRAP Assay}

Once the G-quadruplexes DNA stabilization was established for 1, it was important to test whether the molecule inhibits telomerase activity. To evaluate the abilities of these compounds to inhibit telomerase, the telomeric repeat amplification protocol (TRAP assay) [10,22] was carried out using various amounts of $\mathbf{1}$ (Figure 5). The assay clearly shows that $\mathbf{1}$ is a potent inhibitor of telomerase with activity in the submicromolar range ( $\left.\mathrm{IC}_{50}\right) 0.9 \mu \mathrm{M}$. This result suggests that the TS-primer extends the length to form a tetraplex structure and $\mathbf{1}$ binds to it and stabilizes its structure to inhibit the telomerase reaction. The values obtained from the TRAP assay are comparable to those of previously reported derivatives [10,22]. A number of small ligands have been discovered to inhibit the function of telomerase by stabilizing G-quadruplexes DNA structures [7]. The excellent $\mathrm{IC}_{50}$ for telomerase inhibition by 1 $(0.9 \mu \mathrm{M})$ comes from its binding constant $\left(K>10^{7} \mathrm{M}^{-1}\right)$. It is suggested that this macrocyclic compound 1 may deserve biological assays with cancer cell lines to represent a suitable candidate drug target to DNA quadruplexes. 

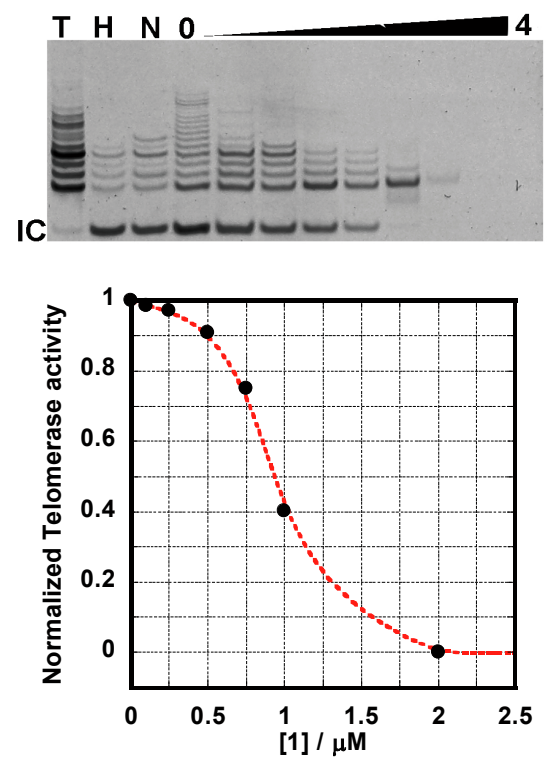

Figure 5. Telomerase inhibition by $\mathbf{1}$. The gel shows the effect of increasing concentrations of $1(0,0.1,0.25,0.5,0.75,1.0,2.0,3.0,4.0 \mu \mathrm{M})$ on telomerase activity. Concentrations of 2.0-4.0 $\mu \mathrm{M} 1$ lead to the disappearance of all PCR products. IC50s were determined as follows: ligand concentration under half telomerase activity with no ligand.

\subsection{FRET-Melting Assay}

The sequence and structural selectivity of different DNA binding agents has been previously explored by use of a thermodynamically rigorous competition assay procedure introduced by Ren and Chaires [23,42]. In this method, different nucleic acid structures are assayed against a common ligand solution. This is a simple method to evaluate specificity toward quadruplexes [43]. It has been already reported that F21T showed a Tm value around $50{ }^{\circ} \mathrm{C}$ [23] that increased by $11{ }^{\circ} \mathrm{C}$ after incorporation of 1 with F21T. Comparison with other G-quadruplexes DNA is shown in Figure 6. Compound $\mathbf{1}$ displays a strong preference for binding to F21T quadruplex structure which corresponds to the human telomeric G-rich motif than other quadruplexes DNA structures.

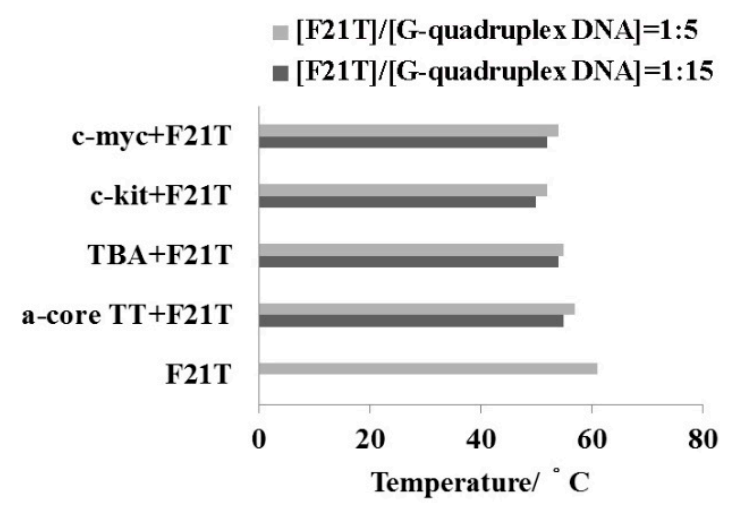

Figure 6. FRET-melting assay of human telomeric DNA (a-coreTT) (1.0 or $3.0 \mu \mathrm{M})$, promoter region's DNA (c-kit \& c-myc) $(1.0$ or $3.0 \mu \mathrm{M})$ and thrombin-binding aptamer (TBA) $(1.0$ or $3.0 \mu \mathrm{M})$ with F21T $(0.2 \mu \mathrm{M})$ in the presence of $1(0.4 \mu \mathrm{M})$. Experiments were performed at $25^{\circ} \mathrm{C}$ in $100 \mathrm{mM}$ Tris- $\mathrm{HCl}$ buffer $\mathrm{pH} 7.4$ containing $150 \mathrm{mM} \mathrm{KCl}$. 


\subsection{Computer Modeling}

The computer-modeling structures consisting of $\mathbf{1}$ with mixed hybrid types G-quadruplex DNA (a-core) are shown in Figure 7. In this article we proposed a model involving an end staking binding mode between 1 and mixed hybrid types G-quadruplex DNA (a-core), which are consistent with our previously published article [22]. The computer modeling showed that the $\mathbf{1}$ molecule stacked and bound to different G-quartet plane of mixed hybrid types G-quadruplex DNA (a-core).
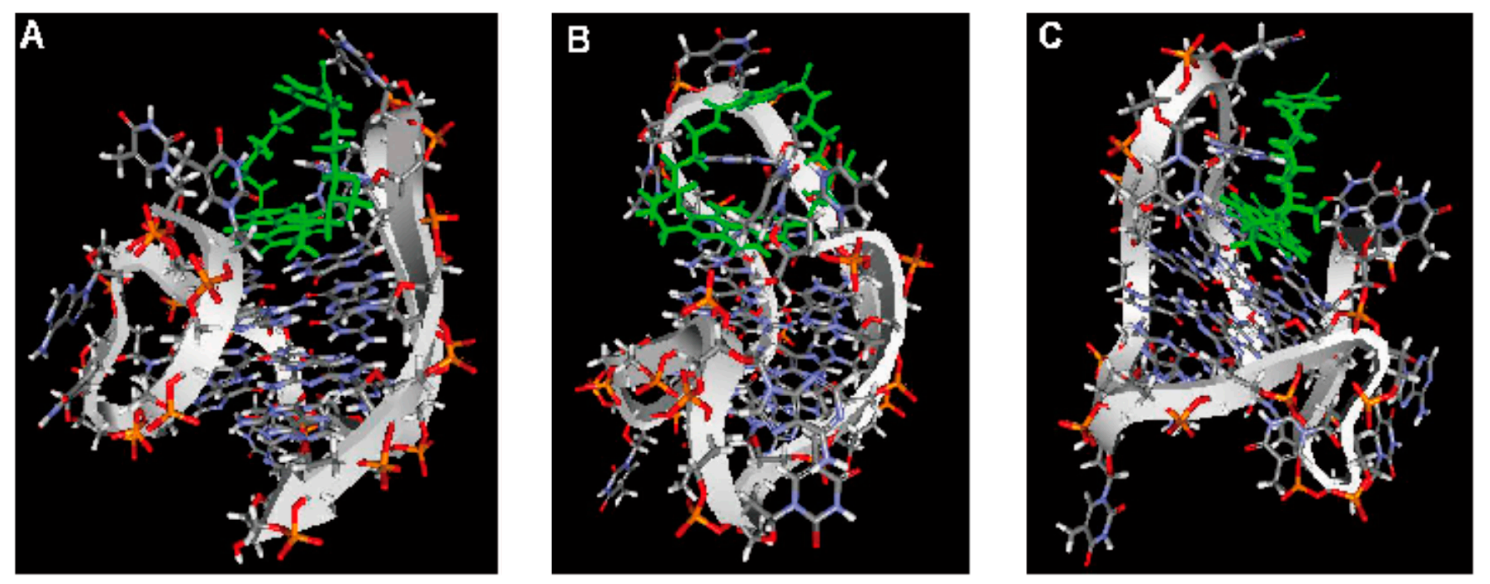

Figure 7. Computer modeling of $\mathbf{1}$ interaction with mixed hybrid G-quadruplex DNA structure (A-C).

\section{Experimental Section}

\subsection{Materials}

The seven G-rich oligonucleotides: a-core (5'-AGGG(TTAGGG)3-3'), a-coreTT (5'-AGGG (TTAGGG) ${ }_{3}$ TT-3'), TBA (5'-GGTTGGTGTGGTTGG-3'), c-kit (5'-AGGGAGGGCGCTGGGAG GAGGAGGG-3'), c-myc (5'- TGAGGGTGGGGAGGGTGGGGAA-3') and dsDNA composed of two complementary strands: (5'-GGGAGGTTTCGC-3') and (5'-GCGAAACCTCCC-3') were purchased from Genenet Co. (Fukuoka, Japan) and used without further purification. The following extinction coefficients were used for quantification of nucleic acid solutions (unit of $\varepsilon$ was $\mathrm{M}^{-1} \mathrm{~cm}^{-1}$ ): 114,000 for 5'-GGGAGGTTTCGC-3'; 108,600 for 5'-GCGAAACCTCCC-3'; 228,500 for a-core (5'-AGGG (TTAGGG)3-3'); 245,100 for a-coreTT (5'-AGGG(TTAGGG) 3 TT-3'); 143,300 for TBA (5'-GGTTG GTGTGGTTGG-3'); 260,100 for c-kit (5'-AGGGAGGGCGCTGGGAGGAGGAGGG-3'); 229,900 for c-myc (5'-TGAGGGTGGGGAGGGTGGGGAA-3'). Before use, oligonucleotide solutions in $50 \mathrm{mM}$ Tris- $\mathrm{HCl}$ buffer ( $\mathrm{pH} 7.4$ ) containing $100 \mathrm{mM} \mathrm{NaCl}$ or $\mathrm{KCl}$ were heated to $95{ }^{\circ} \mathrm{C}$ and annealed by slowly cooling to room temperature. Guanine-rich telomere oligonucleotide sequence (5'-d-GGGTTAGGGTTAGGGTTAGGG3'), dual label with FAM (fluorescent donor) and TAMRA (fluorescent acceptor) at the $5^{\prime}$ and $3^{\prime}$ end, called 'F21T', respectively, were purchased from Sigma-Aldrich (St. Louis, MO, USA). The synthesis procedure of $\mathbf{1}$ was described in detail in a previous article [33]. Compound 2 was synthesized as described previously [44]. The $2.0 \mathrm{M} \mathrm{KCl}$, and $5.0 \mathrm{M} \mathrm{NaCl}$ aqueous solutions were obtained from Life Technologies (Carlsbad, CA, USA). 1.0 M Tris-HCl ( $\mathrm{pH}$ 7.4) buffer was obtained from Sigma-Aldrich. GoTaq Hot Start polymerase was purchased from Promega (Madison, WI, USA). TRAPese kit was obtained from EMD Millipore (Billerica, MA, USA). 


\subsection{UV-Vis Titration Experiments}

Absorption spectra were measured on a U-3310 spectrophotometer (Hitachi, Tokyo, Japan) with a 1 cm path-length quartz cell and were recorded in the 200-600 nm range at $25{ }^{\circ} \mathrm{C}$. UV-Vis absorption titrations were carried out by the stepwise addition of $200 \mu \mathrm{M} /$ strand of G-quadruplexes DNA or dsDNA solution to a UV-cell containing $5.0 \mu \mathrm{M}$ solutions of $\mathbf{1}$ or $\mathbf{2}$. The measurements were performed in a $50 \mathrm{mM}$ Tris- $\mathrm{HCl}$ buffer ( $\mathrm{pH}$ 7.4) containing $100 \mathrm{mM} \mathrm{NaCl}$ or $\mathrm{KCl}$. Binding data obtained from spectrophotometric titration of increasing concentrations of drug to a fixed concentration of DNA was cast into the form of a Scatchard plot of $v / C$ against $v$. The Scatchard plot was analyzed by the Scatchard equation: $v / C=K(n-v)$ [31], where $v$ is the stoichiometry (the number of ligand molecules bound per moles of base pair), $\mathrm{C}$ is the free ligand concentration, $K$ is the observed binding constant, and $n$ is the number of base pairs excluded by the binding of a single ligand molecule. For duplex oligonucleotides saturation of binding curves was not achieved, so $K$ values were estimated using Benesi-Hildebrand method $1 / \Delta \mathrm{Abs}=1 /(l \Delta \varepsilon$ [ligand] $)+1 /(n K l \Delta \varepsilon$ [ligand] $) \times(1 / \mathrm{DNA})$ [32] with the assumption that the ligand/oligonucleotide complex with 1:1 stoichiometry is formed (Table1), where $\Delta \varepsilon$ is a molar absorptivity change of ligand and $l$ is $1 \mathrm{~cm}$. Scatchard plots were prepared using absorption changes at the specific wavelength $383 \mathrm{~nm}$ upon the addition of various concentrations of dsDNA. Scatchard plots were prepared using the data in a range of approximately 30\%-80\% bound region of 1 and dsDNA. The binding data were analyzed with KaleidaGraph software, using the Levenberg-Marquardt algorithm to determine parameters $K_{\mathrm{b}}$ and $n$.

\subsection{Circular Dichroism (CD) Spectral Measurements}

Various concentrations ( 5.0 to $50 \mu \mathrm{M}$ ) of $\mathbf{1}$ or $\mathbf{2}$ were added to $1.5 \mu \mathrm{M} /$ base pair G-quadruplexes DNA in a $50 \mathrm{mM}$ Tris- $\mathrm{HCl}$ buffer ( $\mathrm{pH}$ 7.4) containing $100 \mathrm{mM} \mathrm{NaCl}$ or $\mathrm{KCl}$ at $25^{\circ} \mathrm{C}$, and $\mathrm{CD}$ spectra taken at a scan rate $50 \mathrm{~nm} / \mathrm{min}$ on a J-820 spectropolarimeter (Jasco, Tokyo, Japan). Other conditions were: response $2 \mathrm{~s}$, data interval $0.1 \mathrm{~nm}$, sensitivity $100 \mathrm{mdeg}$, band width $2 \mathrm{~nm}$, and scan number 4 times.

\subsection{Thermal Melting Experiments}

Melting curves of G-quadruplexes DNA or dsDNA were measured on a Hitachi 3300 spectrophotometer (heating rate of $0.5^{\circ} \mathrm{C} / \mathrm{min}$ to $90{ }^{\circ} \mathrm{C}$ ) or Jasco J-820 spectrophotometer (response, $100 \mathrm{mdeg}$; response, $8 \mathrm{~s}$; data collecting interval, $0.5{ }^{\circ} \mathrm{C}$; bandwidth, $2 \mathrm{~nm}$ ) equipped with a temperature controller, respectively. The melting curves based on circular dichroism (CD) at $290 \mathrm{~nm}$ of a-core, a-coreTT, and TBA, $262 \mathrm{~nm}$ of c-kit and c-myc or $260 \mathrm{~nm}$ of dsDNA were measured in $50 \mathrm{mM}$ Tris- $\mathrm{HCl}(\mathrm{pH} 7.4)$ containing $100 \mathrm{mM} \mathrm{NaCl}$ or $\mathrm{KCl}$ (for c-kit $20 \mathrm{mM} \mathrm{KCl}$ and for c-myc $5 \mathrm{mM} \mathrm{KCl}$ ). A mixture of $1.5 \mu \mathrm{M}$ a-core, a-coreTT, TBA, c-kit, c-myc, dsDNA and $3.0 \mu \mathrm{M}$ of $\mathbf{1}$ or $\mathbf{2}$ was placed in a cell of $1 \mathrm{~cm}$ in light path length (total $3 \mathrm{~mL}$ ). Ligand-DNA ratio was set at 2:1.

\subsection{TRAP Assay Experiments}

Telomeric repeat amplification protocol (TRAP) assay was performed using published procedure [10,22]. TRAPeze Telomerase Detection Kit from EMD Millipore was used. Briefly, TS forward primer was elongated by telomerase in TRAP buffer (20 mM Tris- $\mathrm{HCl} \mathrm{pH} 8.3,1.5 \mathrm{mM} \mathrm{MgCl}, 63 \mathrm{mM} \mathrm{KCl}, 0.05 \%$ 
Tween 20, $1.0 \mathrm{mM}$ EGTA) containing $0.05 \mathrm{mM}$ dNTPs, $0.4 \mu \mathrm{M}$ TS primer, $0.4 \mu \mathrm{M}$ primer Mixed (RP primer, K1 primer, TSK1 primer) and 2.0 units of GoTaq Hot Start polymerase. The mixture was added to freshly prepared 1 solution from 0.1 to $4.0 \mu \mathrm{M}(0,0.1,0.25,0.5,0.75,1.0,2.0,3.0,4.0 \mu \mathrm{M})$ and a positive control containing no ligand. Firstly, the elongation step was carried out for $60 \mathrm{~min}$ at $30{ }^{\circ} \mathrm{C}$ and it was followed by $5 \mathrm{~min}$ incubation at $95^{\circ} \mathrm{C}$. Secondly, 35 cycles of PCR were performed $\left(94{ }^{\circ} \mathrm{C}, 30 \mathrm{~s}\right.$; $62{ }^{\circ} \mathrm{C}, 1 \mathrm{~min} ; 72{ }^{\circ} \mathrm{C}, 1 \mathrm{~min}$ ). Telomerase extension products were analyzed on a denaturing $12.5 \%$ polyacrylamide vertical gel prepared in $5 \times$ TBE buffer $(89 \mathrm{mM}$ Tris base, $89 \mathrm{mM}$ borate, and $1 \mathrm{mM}$ EDTA, pH 8.0). The electrophoresis was run in $0.7 \times \mathrm{TBE}$ buffer for $2 \mathrm{~h}$ at $200 \mathrm{~V}$. After electrophoresis gel was stained in $1 \times$ GelStar Nucleic Acid Stain (Takara Bio, Shiga, Japan) in $1 \times$ TBE buffer for $30 \mathrm{~min}$ and photographed.

\subsection{FRET-Melting Assay}

Fluorescence-based melting competition assays was performed using a previously published procedure [23]. In more recent experiments, a real-time PCR apparatus (MX3000P, Stratagene, La Jolla, CA, USA; or Sigma-Aldrich SYBR Green or DNA engine Opticon, MJ Research, Waltham, MA, USA) is used, allowing the simultaneous recording of 32-96 independent samples as first proposed by S. Neidle and co-workers [23]. The protocol used for our experiments is the following: a first step of equilibration at the lowest temperature $\left(5 \mathrm{~min}\right.$ at $25^{\circ} \mathrm{C}$ ) and a stepwise increase of $1{ }^{\circ} \mathrm{C}$ every minute for 72 cycles to reach $95^{\circ} \mathrm{C}$. The buffer $100 \mathrm{mM}$ Tris- $\mathrm{HCl}(\mathrm{pH} 7.4)$ containing $150 \mathrm{mM} \mathrm{NaCl}$ or $\mathrm{KCl}$ and $0.4 \mu \mathrm{M} 1$ was used for all experiments. The thermal denaturation profile of the oligonucleotide F21T $(0.2 \mu \mathrm{M})$ and G-quadruplexes DNA (a-coreTT, TBA, c-kit and c-myc) $(1.0$ or $3.0 \mu \mathrm{M})$ were measured in the presence of $1(0.4 \mu \mathrm{M})$. The ratio of F21T and G-quadruplexes DNA was used 1:5 or 1:15 at $0.4 \mu \mathrm{M} 1$. Fluorescence-based melting assays competition measurements were performed with F21T dual label with FAM (fluorescent donor) and TAMRA (fluorescent acceptor) at the $5^{\prime}$ and $3^{\prime}$ end from Sigma-Aldrich at a heating rate of $1{ }^{\circ} \mathrm{C} / \mathrm{min}$. The recording is performed after $1 \mathrm{~min}$ stabilization. Typically three replicate experiments were performed, and average values are reported. Finally, the amount of ligand bound to the DNA was quantified by fluorescence after the digestion of the oligonucleotide ( $\lambda_{\mathrm{ex}}$ and $\lambda_{\mathrm{em}}$ were set to 490 and $520 \mathrm{~nm}$ for oligonucleotides, respectively).

\subsection{Computer Modeling}

Molecular modeling of these complexes was constructed by MOE 2011.10 (http://www.chemcomp.com/). Compound 1 was placed on the binding site of mixed hybrid types G-quadruplex DNA (a-core) and energy minimization of these complexes was carried out. The molecular dynamics calculation of these mineralized complexes was further carried out until 1 was located in the binding site as stable condition. Finally, energy minimization of the complexes was obtained as shown in Figure 7. These calculations were used the force field of MMFF94x.

\section{Conclusions}

We have a synthesized new type of ligand 1, carrying a benzene moiety as linker chain and studied its interaction with different types of G-quadruplexes DNA. We have compared this study with our 
previously reported 3 [10] which has a long linker chain than $\mathbf{1}$. Compound 1 exhibited high binding affinity in the range of $10^{6}-10^{7} \mathrm{M}^{-1}$ to G-quadruplexes DNA and reduced binding affinity to dsDNA. The binding data (Table 1) indicated that $\mathbf{1}$ has 270-fold preferential binding for a-core, 165-fold for a-coreTT, 51-fold for c-kit, 108-fold for c-myc, 95-fold for TBA over dsDNA. The binding stoichiometry of $\mathbf{1}$ for G-quadruplex is 2:1, suggesting a staking binding mode. Compound $\mathbf{1}$ revealed 200 -fold higher binding selectivity compared with our previously reported 3 [10]. We have observed that 1 revealed preferable binding to mixed hybrid types structure of telomeric G-quadruplex DNA (a-core) over parallel types of promoter region's G-quadruplex DNA (c-kit and c-myc) and antiparallel chair types of thrombin binding aptamer (TBA). The CD spectra showed that $\mathbf{1}$ stabilized G-quadruplexes DNA structure. Upon the addition of 1 to a-core the CD spectra showed little change indicating a mixed hybrid structure and little changed to the hybrid-1 type G-quadruplex structure [36]. Thermal melting measurements indicated that $\mathbf{1}$ highly stabilized the G-quadruplexes DNA structure. Compared with our previous report [10], 1 increased $\Delta \mathrm{T}_{\mathrm{m}}$ by $5-8{ }^{\circ} \mathrm{C}$. We have performed competitive assays in order to determine the binding selectivity among the G-quadruplexes DNA, and 1 showed highly preferable stabilization of human telomeric G-quadruplex sequence (F21T). This novel compound 1 can also inhibit the telomerase activity at low submicromolar concentration. These results indicated that $\mathbf{1}$ is an important class of G-quadruplex stabilizing ligand compared with dsDNA.

\section{Supplementary Materials}

Supplementary data (UV-Vis absorption spectra, Job plot analysis of CD spectra, UV-Vis melting curves of dsDNA and competition assay curves) associated with this article can be found, in the online version, at http:/www.mdpi.com/1420-3049/20/06/10963/s1.

\section{Acknowledgments}

This work was supported in part by JSPS KAKENHI, Grant-in-Aid for Exploratory Research Grant Number 15K13748.

\section{Conflicts of Interest}

The authors declare no conflict of interest.

\section{References}

1. Neidle, S. Therapeutic Applications of Quadruplex Nucleic Acid, 1st ed.; Academic Press: London, UK, 2012; pp. 1-15.

2. Avino, A.; Fabrega, C.; Tintore, M.; Eritja, R. Thrombin binding aptamer, more than a simple aptamer: Chemically modified derivatives and biomedical applications. Curr. Pharm. Des. 2012, 18, 2036-2047.

3. Ou, T.; Lu, Y.; Tan, J.; Huang, Z.; Wong, K.; Gu, L. G-Quadruplexes: Targets in Anticancer Drug Design. Chem. Med. Chem. 2008, 3, 690-713.

4. Dai, J.; Carver, M.; Yang, D. Polymorphism of human telomeric quadruplex structures. Biochimie 2008, 90, 1172-1183. 
5. Huppert, J.L. Four-stranded nucleic acids: Structure, function and targeting of G-quadruplexes. Chem. Soc. Rev. 2008, 37, 1375-1384.

6. Haider, S.M.; Neidle, S.; Parkinson, G.N. A structural analysis of G-quadruplex/ligand interactions. Biochimie 2011, 93, 1239-1251.

7. Monchaud, D.; Teulade-Fichou, M.P. A hitchhiker's guide to G-quadruplex ligands. Org. Biomol. Chem. 2008, 6, 627-636.

8. Davis, J.T. G-Quartets 40 Years Later: From 5'-GMP to Molecular Biology and Supramolecular Chemistry. Angew. Chem. Int. Ed. Engl. 2004, 43, 668-698.

9. Nielsen, M.C.; Ulven, T. Macrocyclic G-Quadruplex Ligands. Curr. Med. Chem. 2010, 17, 3438-3448.

10. Czerwinska, I.; Sato, S.; Juskowiak, B.; Takenaka, S. Interactions of cyclic and non-cyclic naphthalene diimide derivatives with different nucleic acids. Bioorg. Med. Chem. 2014, 22, 2593-2601.

11. Hampel, S.M.; Sidibe, A.; Gunaratnam, M.; Riou, J.; Neidle, S. Tetrasubstituted naphthalene diimide ligands with selectivity for telomeric G-quadruplexes and cancer cells. Bioorganic Med. Chem. Lett. 2010, 20, 6459-6463.

12. Marchetti, C.; Minarini, A.; Tumiatti, V.; Moraca, F.; Parrotta, L.; Alcaro, S.; Rigo, R.; Sissi, C.; Gunaratnam, M.; Ohnmacht, S.A.; et al. Macrocyclic naphthalene diimides as G-quadruplex binders. Bioorg. Med. Chem. 2015, in press.

13. Prato, G.; Silvent, S.; Saka, S.; Lamberto, M.; Kosenkov, D. Thermodynamics of Binding of Di- and Tetrasubstituted Naphthalene Diimide Ligands to DNA G-Quadruplex. J. Phys. Chem. B 2015, 119, 3335-3347.

14. Collie, G.W.; Promontorio, R.; Hampel, S.M.; Micco, M.; Neidle, S.; Parkinson, G.N. Structural Basis for Telomeric G-Quadruplex Targeting by Naphthalene Diimide Ligands. J. Am. Chem. Soc. 2012, 134, 2723-2731.

15. Micco, M.; Collie, G.W.; Dale, A.G.; Ohnmacht, S.A.; Pazitna, I.; Gunaratnam, M.; Reszka, A.P.; Neidle, S. Structure-Based Design and Evaluation of Naphthalene Diimide G-Quadruplex Ligands As Telomere Targeting Agents in Pancreatic Cancer Cells. J. Med. Chem. 2013, 56, 2959-2974.

16. Nadai, M.; Doria, F.; Antonio, M.D.; Sattin, G.; Germani, L.; Percivalle, C.; Palumbo, M.; Richter, S.N.; Freccero, M. Naphthalene diimide scaffolds with dual reversible and covalent interaction properties towards G-quadruplex. Biochimie 2011, 93, 1328-1340.

17. Doria, F.; Oppi, A.; Manoli, F.; Botti, S.; Kandoth, N.; Grande, V.; Manet, I.; Freccero, M. A naphthalene diimide dyad for fluorescence switch-on detection of G-quadruplexes. Chem. Commun. 2015, 51, 9105-9108.

18. Doria, F.; Nadai, M.; Folini, M.; Scalabrin, M.; Germani, L.; Sattin, G.; Mella, M.; Palumbo, M.; Zaffaroni, N.; Fabris, D.; et al. Targeting Loop Adenines in G-Quadruplex by a Selective Oxirane. Chem. Eur. J. 2013, 19, 78-81.

19. Doria, F.; Nadai, M.; Folini, M.; Antonio, M.D.; Germani, L.; Percivalle, C.; Sissi, C.; Zaffaroni, N.; Alcaro, S.; Artese, A.; et al. Hybrid ligand-alkylating agents targeting telomeric G-quadruplex Structures. Org. Biomol. Chem. 2012, 10, 2798-2806.

20. Antonio, M.D.; Folini, M.; Richter, S.N.; Bertipaglia, C.; Mella, M.; Sissi, C.; Manlio Palumbo, M.; Freccero, M. Quinone Methides Tethered to Naphthalene Diimides as Selective G-Quadruplex Alkylating Agents. J. Am. Chem. Soc. 2009, 131, 13132-13141. 
21. Nadai, M.; Doria, F.; Germani, L.; Richter, S.N.; Freccero, M. A Photoreactive G-Quadruplex Ligand Triggered by Green Light. Chem. Eur. J. 2015, 21, 2330-2334.

22. Esaki, Y.; Islam, M.M.; Fujii, S.; Sato, S.; Takenaka, S. Design of tetraplex specific ligands: Cyclic naphthalene diimide. Chem. Commun. 2014, 50, 5967-5969.

23. Cian, A.D.; Guittat, L.; Kaiser, M.; Sacca, B.; Amrane, S.; Bourdoncle, A.; Teulade-Fichou, M.P.; Alberti, P.; Lacroix, L.; Mergny, J.L. Fluorescence-based melting assays for studying quadruplex ligands. Methods 2007, 42, 183-195.

24. Ambrus, A.; Chen, D.; Dai, J.; Bialis, T.; Jones, R.A.; Yang, D. Human telomeric sequence forms a hybrid-type intramolecular G-quadruplex structure with mixed parallel/antiparallel strands in potassium solution. Nucleic Acids Res. 2006, 34, 2723-2735.

25. Hansel, R.; Lohr, F.; Trantirkova, S.F.; Bamberg, E.; Trantirek, L.; Dotsch, V. The parallel G-quadruplex structure of vertebrate telomeric repeat sequences is not the preferred folding topology under physiological conditions. Nucleic Acids Res. 2011, 39, 5768-5775.

26. Dai, J.X.; Carver, M.; Hurley, L.H.; Yang, D.Z. Solution structure of a 2:1 quindoline-c-MYC G-quadruplex: Insights into G-quadruplex-interactive small molecule drug design. J. Am. Chem. Soc. 2011, 133, 17673-17680.

27. Phan, A.T.; Kuryavyi, V.; Burge, S.; Neidle, S.; Patel, D.J. Structure of an Unprecedented G-Quadruplex Scaffold in the Human c-kit Promoter. J. Am. Chem. Soc. 2007, 129, 4386-4392.

28. Arora, A.; Maiti, S. Effect of Loop Orientation on Quadruplex-TMPyP4 Interaction. J. Phys. Chem. B 2008, 112, 8151-8159.

29. Macaya, R.F.; Schultze, P.; Smith, F.W.; Roet, J.A.; Feigon, J. Thrombin-binding DNA aptamer forms a unimolecular quadruplex structure in solution. Proc. Natl. Acad. Sci. USA 1993, 90, 3745-3749.

30. Toro, M.; Gargallo, R.; Eritja, R.; Jaumot, J. Study of the interaction between the G-quadruplex-forming thrombin-binding aptamer and the porphyrin 5,10,15,20-tetrakis-( $N$-methyl-4-pyridyl)-21,23H-porphyrin tetratosylate. Anal. Biochem. 2008, 379, 8-15.

31. McGhee, J.D.; vonHippel, P.H. Theoretical aspects of DNA-protein interactions: Co-operative and non-co-operative binding of large ligands to a one-dimensional homogeneous lattice. J. Mol. Biol. 1974, 86, 469-489.

32. Benesi, H.A.; Hildebrand, J.H. A Spectrophotometric Investigation of the Interaction of Iodine with Aromatic Hydrocarbons. J. Am. Chem. Soc. 1949, 71, 2703-2707.

33. Islam, M.M.; Fujii, S.; Sato, S.; Okauchi, T.; Takenaka, S. Thermodynamics and Kinetic Studies in the Binding Interaction of Cyclic Naphthalene Diimide Derivatives with Double Stranded DNAs. Bioorganic Med. Chem. 2015, in press.

34. Phan, A.T.; Kuryavyi, V.; Luu, K.N.; Patel, D.J. Structure of two intramolecular G-quadruplexes formed by natural human telomere sequences in K+ solution. Nucleic Acids Res. 2007, 35, 6517-6525.

35. Luu, K.N.; Phan, A.T.; Kuryavyi, V.; Lacroix, L.; Patel, D.J. Structure of the Human Telomere in K+ Solution: An Intramolecular $(3+1)$ G-Quadruplex Scaffold. J. Am. Chem. Soc. 2006, 128, 9963-9970.

36. Du, Y.; Zhang, D.; Chen, W.; Zhang, M.; Zhou, Y.; Zhou, X. Cationic N-confused porphyrin derivative as a better molecule scaffold for G-quadruplex recognition. Bioorganic Med. Chem. 2010, $18,1111-1116$. 
37. Nagatoishi, S.; Tanaka, Y.; Tsumoto, K. Circular dichroism spectra demonstrate formation of the thrombin-binding DNA aptamer G-quadruplex under stabilizing-cation-deficient conditions. Biochem. Biophys. Res. Commun. 2007, 352, 812-817.

38. Dash, J.; Shirude, P.S.; Hsu, S.D.; Balasubramanian, S. Diarylethynyl Amides That Recognize the Parallel Conformation of Genomic Promoter DNA G-Quadruplexes. J. Am. Chem. Soc. 2008, 130, $15950-15956$.

39. Wei, C.; Wang, Y.; Zhang, M. Synthesis and binding studies of novel di-substituted phenanthroline compounds with genomic promoter and human telomeric DNA G-quadruplexes. Org. Biomol. Chem. 2013, 11, 2355-2364.

40. Dhamodharan, V.; Harikrishna, S.; Jagadeeswaran, C.; Halder, K.; Pradeepkumar, P.I. Selective G-quadruplex DNA Stabilizing Agents Based on Bisquinolinium and Bispyridinium Derivatives of 1,8-Naphthyridine. J. Org. Chem. 2012, 77, 229-242.

41. Hayden, K.L.; Graves, D.E. Addition of Bases to the 5'-end of Human Telomeric DNA: Influences on Thermal Stability and Energetics of Unfolding. Molecules 2014, 19, 2286-2298.

42. Ragazzon, P.; Chaires, J.B. Use of competition dialysis in the discovery of G-quadruplex selective ligands. Methods 2007, 43, 313-323.

43. Fichou, M.P.T.; Carrasco, C.; Guittat, L.; Bailly, C.; Alberti, P.; Mergny, J.L.; David, A.; Lehn, J.M.; Wilson, W.D. Selective Recognition of G-Quadruplex Telomeric DNA by a Bis(quinacridine) Macrocycle. J. Am. Chem. Soc. 2003, 125, 4732-4740.

44. Tanious, F.A.; Yen, S.F.; Wilson, W.D. Kinetic and Equilibrium Analysis of a Threading Intercalation Mode: DNA Sequence and Ion Effects. Biochemistry 1991, 30, 1813-1819.

Sample Availability: Samples of the compounds $\mathbf{1}$ are available from the authors.

(C) 2015 by the authors; licensee MDPI, Basel, Switzerland. This article is an open access article distributed under the terms and conditions of the Creative Commons Attribution license (http://creativecommons.org/licenses/by/4.0/). 